\title{
Growth and Physical Characterization of Polygon Prismatic Hollow Zn-ZnO Crystals
}

\author{
Kun-Ho Liu, Chin-Ching Lin, and San-Yuan Chen* \\ Department of Materials Science and Engineering, National Chiao Tung University, \\ 1001 Ta-hsueh Road, Hsinchu, Taiwan
}

\begin{abstract}
A hierarchical polygon prismatic $\mathrm{Zn}-\mathrm{ZnO}$ core-shell structure was grown on silicon by combining liquid-solution colloidals together with the vapor-gas growth process. Zn colloidals with a diameter of 5-10 nm synthesized from $\mathrm{Zn}\left(\mathrm{ClO}_{4}\right)_{2}$ precursor solution were used as nucleation seeds for the growth of $\mathrm{Zn}$ polygon prismatic nanocrystals. Depending on carrier gas and annealing conditions, the polygon prismatic Zn crystals having morphology from hollow to dense configuration can be manipulated. Moreover, after prolonged thermal treatment at 300-400 ${ }^{\circ} \mathrm{C}$, polygon prismatic hollow $\mathrm{ZnO}-\mathrm{Zn}$ crystals with a dimension from nanometer to micrometer can be obtained. The room-temperature photoluminescence spectra show that the hollow $\mathrm{ZnO}-\mathrm{Zn}$ crystals have a weak ultraviolet (UV) emission at $380 \mathrm{~nm}$ and a strong green emission at $500 \mathrm{~nm}$. However, the intensity of the UV emission can be improved by postannealing the $\mathrm{Zn}-\mathrm{ZnO}$ core-shell structure in an oxygen atmosphere to form hollow $\mathrm{ZnO}$ crystals.
\end{abstract}

\section{Introduction}

The zinc oxide $(\mathrm{ZnO})$ nanostructure is one of the most promising materials for optoelectronic applications, including photodetectors ${ }^{1}$ solar cells,,${ }^{2}$, and nanolasers ${ }^{3}$ because it possesses a direct band gap of $3.37 \mathrm{eV}$ and strong exciton binding energy of $60 \mathrm{meV}$ which can ensure an efficient exciton emission at room temperature.

During the past few years, many different morphological $\mathrm{ZnO}$ nanostructures, including nanowires, ${ }^{4}$ nanorods,${ }^{5}$ nanocables,${ }^{6}$ and nanobelts, ${ }^{7}$ have been fabricated. Moreover, various techniques such as thermal decomposition, ${ }^{8}$ vapor-phase transport, ${ }^{9}$ and metalorganic chemical vapor deposition (MOCVD) ${ }^{10}$ have been developed to synthesize $\mathrm{ZnO}$ nanostructures. The vapor-liquid-solid (VLS) method is a common approach to grow nanostructures, and many researchers have tried to control the process parameters to produce nanocrystals of technologically useful geometry. ${ }^{11,12}$ Many efforts have been successfully invested in the growth of $\mathrm{ZnO}$ nanorods or nanowires. However, this method has been based on high-temperature processing. On the other hand, although liquid-phase chemical synthesis can be also used to grow nanorods at a lower temperature, different anisotropic shapes of nanocrystals have been limited. So far, only rod-based morphology has been obtained.

One of the challenges in materials is to control the structure of materials on specific nanomorphologies. ${ }^{13,14}$ Especially, both controlled shape and size of inorganic nanocrystals have a strong influence on electrical and optical properties..$^{15,16}$ In the past, Yamada et al. developed $\mathrm{ZnO}$ fine crystals with various growth forms by rapid condensation of the high-temperature ultrasupersaturated gas generated from $\mathrm{ZnO}$ powder by means of the conically converging shock-wave technique in $1989 .{ }^{17}$ Recently, it was reported that $\mathrm{ZnO}$ and beltlike $\mathrm{Zn}$ particles can be synthesized via thermolysis of the

* To whom correspondence should be addressed. Tel:+ 886-35731818. Fax: +886-3-5725490. E-mail: sychen@cc.nctu.edu.tw. molecular precursors $[\mathrm{MeZnOSiMe}]_{4}$ and $\left[\mathrm{Zn}\left(\mathrm{OSiMe}_{3}\right)_{2}\right]_{n}$ in the temperature range of $160-500{ }^{\circ} \mathrm{C} .{ }^{18}$ Obviously, several metal-organic precursors in the solid state and/ or solution can be used for the synthesis of $\mathrm{Zn}$ - and/or nanocrystalline $\mathrm{ZnO}$ particles.

In contrast to conventional processes, a novel process was proposed to combine the aforementioned vaporgas with liquid-solution methods for growing polygon prismatic $\mathrm{Zn}$ and $\mathrm{ZnO}$ crystals with a dimension from nanometer to micrometer. The liquid-solution method supplies the uniform nanoseeds to serve as nuclei, and the subsequent vapor-gas-phase process provides the $\mathrm{Zn}$ source for the growth of $\mathrm{Zn}$ or $\mathrm{ZnO}$ crystals.

Furthermore, it was found that depending on growth conditions such as temperature, time, and atmosphere, dense and hollow polygon prismatic Zn crystals can be developed. ${ }^{19}$ Therefore, both physical characterization and photoluminescence properties of the polygon prismatic hollow $\mathrm{Zn}-\mathrm{ZnO}$ crystals will be investigated in this work.

\section{Experimental Methods}

Polygon prismatic $\mathrm{ZnO}$ and $\mathrm{Zn}$ nanocrystals were synthesized using colloidal Zn particles and a physical vapor transport system. The colloidal $\mathrm{Zn}$ prepared in methanol with 50 $\mathrm{mL}$ of $10^{-2} \mathrm{M} \mathrm{Zn}\left(\mathrm{ClO}_{4}\right)_{2}$ solution was added to $442 \mathrm{~mL}$ of methanol plus $8 \mathrm{~mL}$ of $5 \mathrm{M} \mathrm{NaOH}$ and left for $24 \mathrm{~h}$ overnight. A transparent solution was finally obtained with its light absorption starting at $350 \mathrm{~nm}$. In this work, $\mathrm{ZnO}$ and graphite powders were used for the growth source of $\mathrm{Zn}$ nanocrystals and ball-mixed in ethanol for $15 \mathrm{~h}$. An alumina tube was mounted inside a high-temperature tube furnace with the source material placed on an alumina boat and positioned at the center of the alumina tube. Subsequently, the Si substrate was spin-coated with various concentrations of the colloidal $\mathrm{Zn}$ and then located downstream of the carrier gas flow in the alumina tube where the tube was sealed and evacuated by a mechanical rotary pump to a pressure of 80 mTorr. Highpurity Ar was used as the carrier gas with a flow rate of 10 $\mathrm{sccm}$, and the reaction was carried out at $1100^{\circ} \mathrm{C}$ for $0.5-5 \mathrm{~h}$ to form polygon prismatic hollow $\mathrm{Zn}$ crystals at the substrate temperatures of $300-400{ }^{\circ} \mathrm{C}$. The temperature in both temperature zones was measured and corrected with K-type 


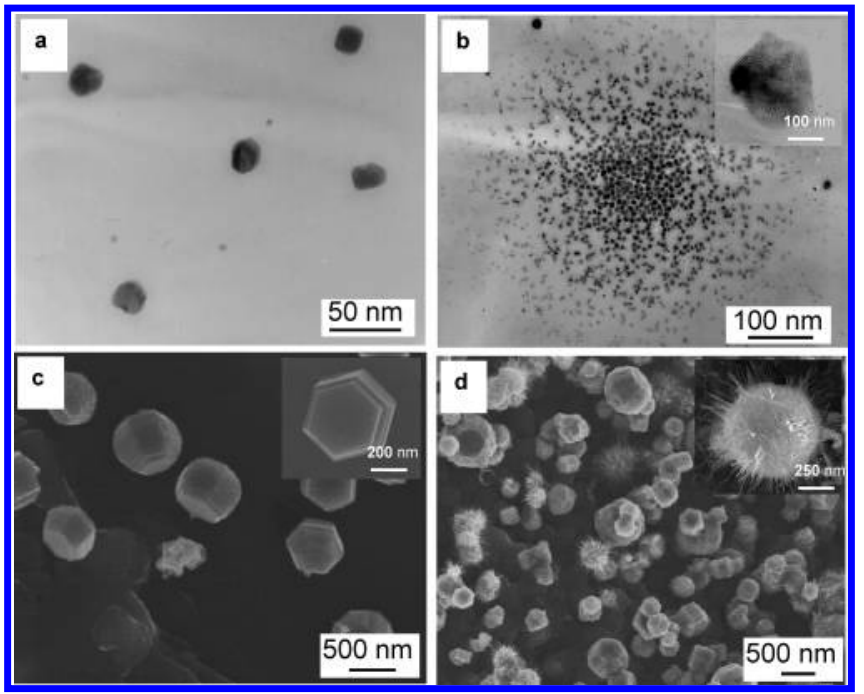

Figure 1. Morphology development of polygon prismatic compact $\mathrm{Zn}$ crystals as a function of growth time at $300{ }^{\circ} \mathrm{C}$ in an Ar atmosphere. (a) TEM image of polygon prismatic $\mathrm{Zn}$ nanoparticles $(<30 \mathrm{~nm})$ formed by the thermal vapor process in the initial growth stage. (b) Polygon prismatic $\mathrm{Zn}$ clusters are attracted together in $0.5 \mathrm{~h}$ and arranged into a polygonbased shape (inset). Also shown is the morphology of polygon prismatic Zn crystals in (c) $2 \mathrm{~h}$ and (d) $4 \mathrm{~h}$.

thermocouples. The data error was about $5-10{ }^{\circ} \mathrm{C}$. After thermal treatment, the $\mathrm{Zn}$ polygon prismatic nanocrystals were taken out and then annealed at $350{ }^{\circ} \mathrm{C}$ in a pure oxygen atmosphere $(5 \mathrm{~N})$ for different periods of time to form $\mathrm{ZnO}$ on the surface of the $\mathrm{Zn}$ hollow crystals. For comparison, a mixture gas of Ar and oxygen was also used for the crystal growth.

The deposited material was analyzed by field emission scanning electron microscopy (FE-SEM, S-4100), and the crystal structure was determined using X-ray diffraction (XRD, Siemens D5000). The depth profile of polygon prismatic $\mathrm{ZnO}-$ Zn crystals was measured using AES (Auger nanoprobe electron spectroscopy, Auger 670 PHI Xi). Transmission electron microscopy (TEM, Philips TECNAI 20) with energydispersive X-ray spectroscopy (EDS) operated at $200 \mathrm{keV}$ was also used for structural analysis. Photoluminescence measurement was performed by excitation from a $325 \mathrm{~nm} \mathrm{He}-\mathrm{Cd}$ laser at room temperature.

\section{Results and Discussion}

Figure 1 shows the typical SEM and TEM images of the polygon prismatic $\mathrm{Zn}$ nanocrystals as a function of growth time at $300{ }^{\circ} \mathrm{C}$. In an initial growth stage $(<0.5$ h), many nanoparticles with particle size smaller than $30 \mathrm{~nm}$ were identified and are shown in Figure 1a. When the growth time is extended over $30 \mathrm{~min}(0.5 \mathrm{~h})$, those nanoparticles are gradually agglomerated together to form a polygon-based shape as shown in Figure $1 \mathrm{~b}$ that is close to the composing-crystals shown in the inset of Figure $1 \mathrm{~b}$ with a diameter around 150 $\mathrm{nm}$. Later, a stable compact structure of polygon prismatic $\mathrm{Zn}$ nanocrystals was developed in Figure 1c. According to our previous studies, the nucleation size of the polygon prismatic crystals is related to the concentration of the $\mathrm{Zn}\left(\mathrm{ClO}_{4}\right)_{2}$ solution. As a higher colloidal concentration was used, the agglomerate degree among the nanoparticles was apparently increased. Furthermore, a larger number of agglomerate regions with a bigger size of the structure by self-assembly of $\mathrm{Zn}$ nanocrystals were observed. ${ }^{19}$ The diameter of the polygon Zn crystals can be tuned from $100 \mathrm{~nm}$ to $1 \mu \mathrm{m}$ by simply varying the growth temperature and time. However, the growth mechanism of the crystals is not the focus of this work and will be reported elsewhere. ${ }^{20}$ When the growth time exceeds $3 \mathrm{~h}$, it was found that anisotropic structures such as wires and rods were grown on the surface of the crystals, as shown in Figure $1 d$. In addition, the surface became rough and many pores were formed on the surface. This observation suggests that above a critical growth time, many defects would be created on the surface of polygon prismatic crystals because zinc metal becomes unstable and sublimated in an Ar atmosphere. Then, the defects could act as nucleation sites to grow anisotropic structure because of the cavitation effect.

On the other hand, as the sample was treated at 350 ${ }^{\circ} \mathrm{C}$, Figure 2a shows that the polygon-based $\mathrm{Zn}$ crystals were rapidly developed in an initial growth stage $(t<$ $0.5 \mathrm{~h}$ ), but with porous structure formed inside the crystals. With increasing growth time up to 2 h, Figure $2 \mathrm{~b}$ indicates that the polygon prismatic $\mathrm{Zn}$ crystals with a hollow structure have been formed. However, the polygon prismatic structure becomes unstable and tends to form spherelike morphology as the growth time exceeds $3 \mathrm{~h}$. The formation mechanism for both compact and hollow polygon prismatic $\mathrm{Zn}$ structure is given in ref 20 and is briefly described as follows. After the $\mathrm{Zn}$ $\left(\mathrm{ClO}_{4}\right)_{2}$ solution containing $\mathrm{Zn}$ colloidals was deposited on the $\mathrm{Si}$ substrate, these nuclei would cap these $\mathrm{Zn}$ molecules to develop the nanocrystals when Zn sources were transported by a thermal evaporation process. Moreover, Zn nanocrystals would be assembled by attractive force to form a base of polygon prismatic crystals and organized in a compact hexagonal network. At a lower temperature below $300^{\circ} \mathrm{C}$, a compact polygon prismatic $\mathrm{Zn}$ crystal was maintained due to solidification of liquid droplets. However, as the sample was treated at $300-400{ }^{\circ} \mathrm{C}$ in $\mathrm{Ar}$, sublimation of the $\mathrm{Zn}$ core and surface oxidation of the $\mathrm{Zn}$ crystal would result in the formation of a hollow structure. If a higher growth temperature, i.e., $500{ }^{\circ} \mathrm{C}$, was used, the whole structure almost collapsed (not shown here) because the melting point of $\mathrm{Zn}$ is about $410{ }^{\circ} \mathrm{C}$.

Figure 3 shows the X-ray diffraction spectra of the $\mathrm{Zn}$ crystals. As the sample was grown in pure argon at $350{ }^{\circ} \mathrm{C}$ for $2 \mathrm{~h}$, Figure 3 a illustrates that only $\mathrm{Zn}$ phase can be detected from the polygon prismatic hollow $\mathrm{Zn}$ crystals. When the Zn crystals were then postannealed at the same temperature $\left(350{ }^{\circ} \mathrm{C}\right)$ for $2 \mathrm{~h}$ in an oxygen atmosphere without $\mathrm{Zn}$ source supplied, it was found that zinc oxide was developed from the polygon prismatic hollow crystals as evidenced in the XRD pattern of Figure 3b. Furthermore, prolonged oxygen annealing of $30 \mathrm{~h}$ at $350{ }^{\circ} \mathrm{C}$ promotes the formation of $\mathrm{ZnO}$. As evidenced in Figure 3c, only $\mathrm{ZnO}$ phase and an almost negligible $\mathrm{Zn}$ peak are observed, indicating that the polygon prismatic hollow Zn crystals were nearly oxidized into $\mathrm{ZnO}$. A similar transformation from $\mathrm{Zn}$ into $\mathrm{ZnO}$ was also reported in the literature. ${ }^{21} \mathrm{Li}$ et al. treated $\mathrm{Zn}$ nanowires grown by the anodic alumina oxide (AAO) process in air at $300^{\circ} \mathrm{C}$ for $35 \mathrm{~h}$ and found that $\mathrm{ZnO}$ nanowires could be formed.

During our systematical exploration of the formation process of $\mathrm{Zn}-\mathrm{ZnO}$ crystals, it seems that there exists 


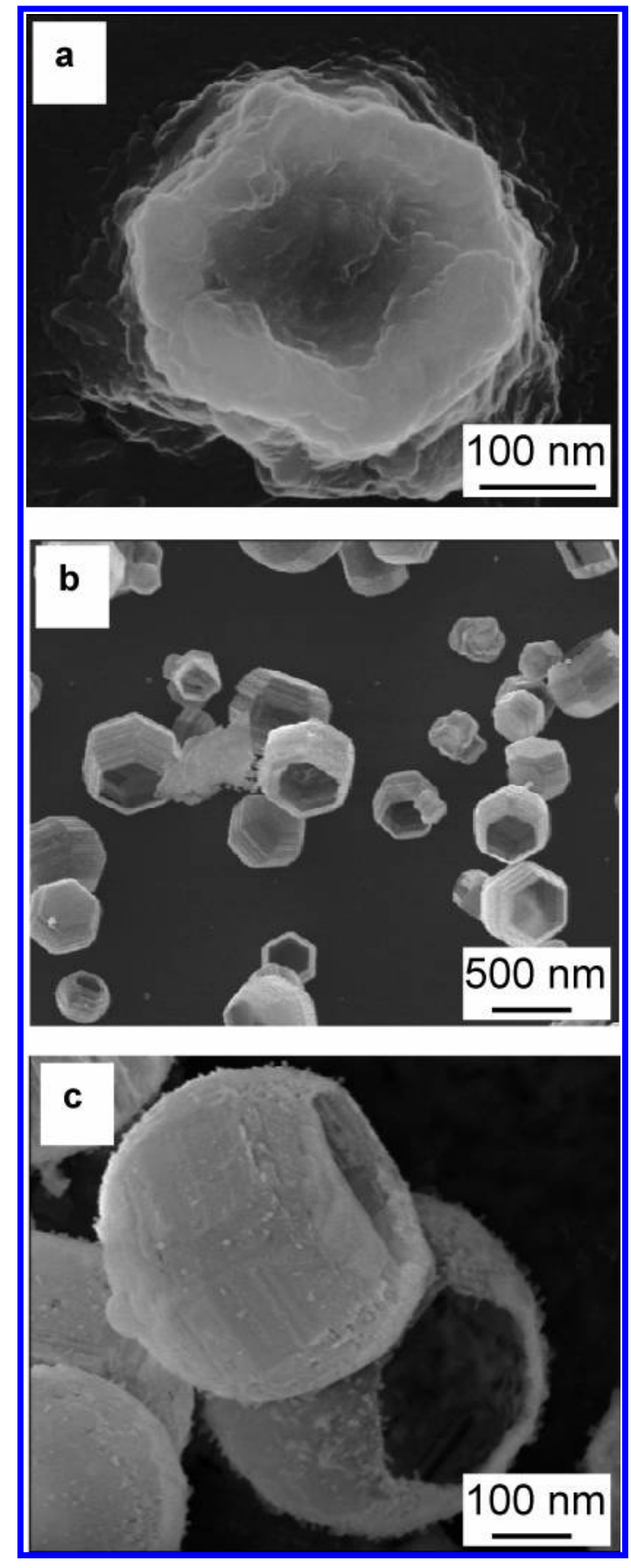

Figure 2. Morphology development of polygon prismatic hollow $\mathrm{Zn}$ crystals as a function of growth time at $350{ }^{\circ} \mathrm{C}$ in an Ar atmosphere. (a) A porous net-structure was formed in the initial growth stage of $t<0.5 \mathrm{~h}$, (b) $2 \mathrm{~h}$, and (c) $3 \mathrm{~h}$.

a transition temperature around $300-350{ }^{\circ} \mathrm{C}$ from compact to hollow structure for the Zn crystals grown in an Ar atmosphere. Different structural morphologies of the $\mathrm{Zn}-\mathrm{ZnO}$ crystals can be achieved by carefully controlling the growth temperature and atmosphere. Furthermore, as the crystals were grown at $320^{\circ} \mathrm{C}$ for $2 \mathrm{~h}$ in Ar atmospheres, it was found that the Zn crystals exhibit compact structure with a morphology similar to that grown at $300{ }^{\circ} \mathrm{C}$. However, as analyzed by AES where a polygon prismatic $\mathrm{Zn}$ crystal with a dimension of 700-850 $\mathrm{nm}$ in length and $300-400 \mathrm{~nm}$ in diameter was used, Figure 4a illustrates that the signal of $\mathrm{Zn}$ element only appears from the surface to a depth of 75
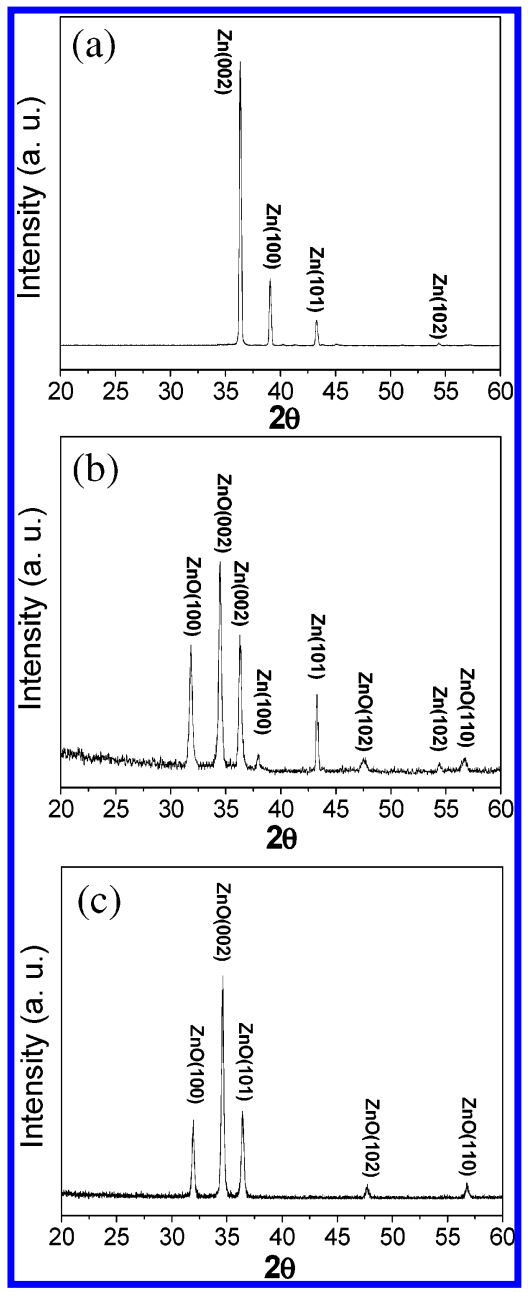

Figure 3. XRD patterns of the $\mathrm{Zn}$ crystals grown (a) in pure argon for $2 \mathrm{~h}$, (b) after postannealing in an oxygen atmosphere at $350{ }^{\circ} \mathrm{C}$ for $2 \mathrm{~h}$, and (c) after prolonged oxygen annealing at $350{ }^{\circ} \mathrm{C}$ for $30 \mathrm{~h}$ to form $\mathrm{ZnO}$ crystals.

$\mathrm{nm}$ and the oxygen element signal is detected only near the surface region. According to the above statement, if the polygon prismatic Zn crystals on a Si substrate are in a dense compact structure, the signal of $\mathrm{Zn}$ element should be extended over the whole Zn crystal $(700 \mathrm{~nm})$. In other words, at such a short sputtering time of $300 \mathrm{~s}$ (less than $\sim 1200 \mathrm{~s}$ ) or distance of $75 \mathrm{~nm}$ (smaller than $\sim 700 \mathrm{~nm}$ ) from the surface, the detected signal should be $\mathrm{Zn}$ instead of $\mathrm{Si}$ if it is compact $\mathrm{Zn}$ crystal. However, actually, only Si signal can be detected for the sputtering time of $300 \mathrm{~s}$. This indicates that prior to the formation of the hollow Zn structure, many pores have been developed inside the $\mathrm{Zn}$ crystal at this temperature due to the sublimation and out-diffusion of $\mathrm{Zn}$ crystals.

When a mixture carrier gas, i.e., $\mathrm{Ar} / \mathrm{O}_{2}$, was employed during the growth process of the Zn crystals, although a compact polygon prismatic $\mathrm{Zn}$ crystal was observed, the depth profile of the polygon prismatic $\mathrm{Zn}$ crystals in Figure 4b exhibits different characteristics compared to that of the sample grown in pure Ar (Figure 4a). The depth profile of $\mathrm{Zn}$ element was measured around 700 $\mathrm{nm}$, corresponding to the dimension of the crystals, and this demonstrates that the polygon prismatic Zn crystal has a dense compact structure. In addition, the intensity of the oxygen signal is stronger than that grown in a 


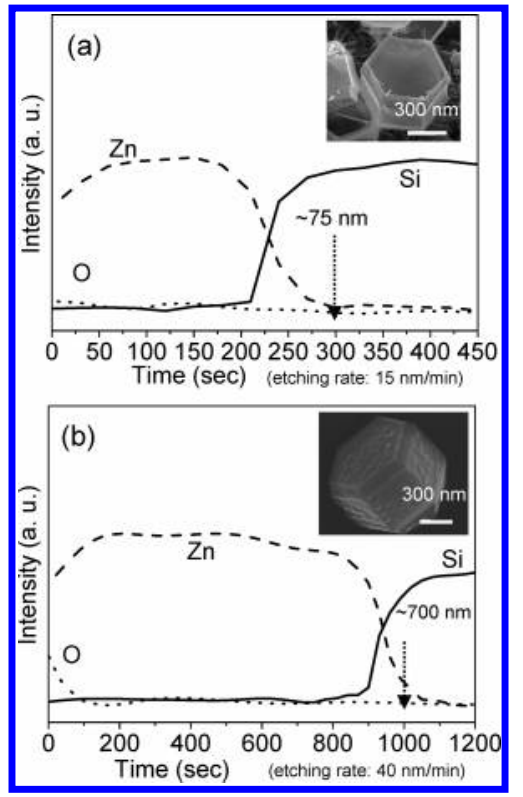

Figure 4. Depth profiles of polygon prismatic $(\mathrm{ZnO})-\mathrm{Zn}$ crystals grown (a) in pure argon and (b) in a mixture gas of argon and oxygen at $300{ }^{\circ} \mathrm{C}$ for $2 \mathrm{~h}$. The inset is the FE-SEM images of these $(\mathrm{ZnO}-) \mathrm{Zn}$ crystals.

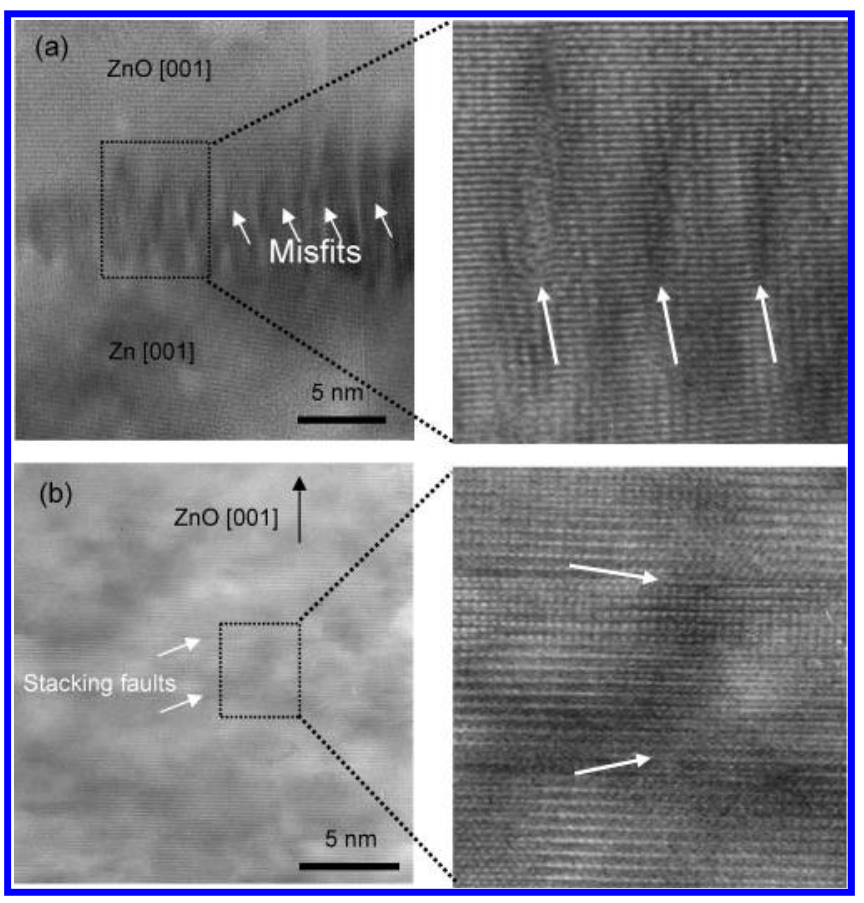

Figure 5. High-resolution TEM images of (a) hollow heterostructural $\mathrm{Zn} / \mathrm{ZnO}$ core-shell nanocrystals and (b) $\mathrm{ZnO}$ nanocrystals. A magnified picture of the corresponding regions is also illustrated. The white arrowheads indicate the locations of the misfits or structure faults.

pure Ar atmosphere. The zinc oxide layer was estimated to be about $40 \mathrm{~nm}$. Although the exact formula composition cannot be calculated, it indicates that more oxidation has taken place on the surface of the polygon prismatic $\mathrm{Zn}$ crystals. This reveals that $\mathrm{ZnO}$ phase has been formed on the surface of the polygon prismatic $\mathrm{Zn}$ crystals and plays a role in prohibiting the sublimation of $\mathrm{Zn}$. As shown in Figure 5a, the cross-sectional highresolution TEM analysis of the polygon prismatic hollow $\mathrm{Zn}$ crystals demonstrates that $\mathrm{ZnO}$ has been formed on the surface of hollow $\mathrm{Zn}$ crystals. The singular fringe

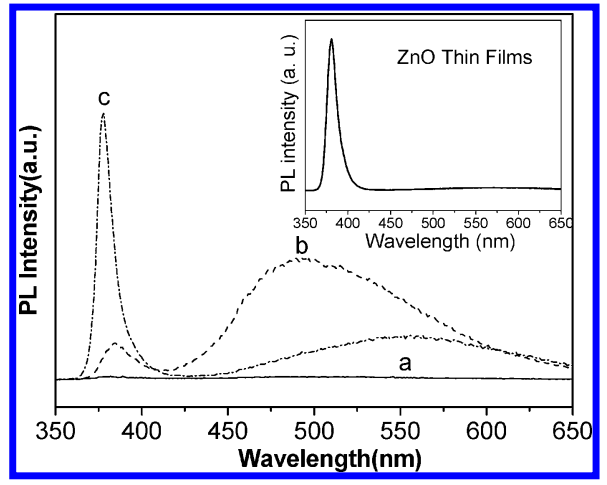

Figure 6. PL spectra recorded at room temperature with $\mathrm{Zn}$ or $\mathrm{ZnO}$ crystals (a) grown in pure $\mathrm{Ar}$, (b) annealed in air for a short period time of $2 \mathrm{~h}$, and (c) postannealed in an oxygen atmosphere at $350{ }^{\circ} \mathrm{C}$ for $30 \mathrm{~h}$. The PL spectra of $\mathrm{ZnO}(002)$ thin films are shown in the inset for comparison.

spacing of the $\mathrm{Zn}$ was measured to be $0.24 \mathrm{~nm}$, which agrees well with the (100) spacing of wurtzite-Zn, while the value of the surface $\mathrm{ZnO}$ is about $0.28 \mathrm{~nm}$, which agrees well with the (100) spacing of wurtzite-ZnO. However, it was found that there exists a regular array of misfits (marked with arrows) at the interface between $\mathrm{Zn}$ and $\mathrm{ZnO}$. The corresponding region of the structure fault in the $\mathrm{Zn} / \mathrm{ZnO}$ core-shell is also magnified to reveal the misfits. These developed misfits possibly serve to accommodate the relatively large lattice mismatch between $\mathrm{Zn}$ and $\mathrm{ZnO}$ (17\%). In contrast, as the $\mathrm{Zn}$ crystals were treated with prolonged oxygen annealing, Figure $5 \mathrm{~b}$ reveals that in addition to the lattice images of $\mathrm{ZnO}$, many plane defects (stacking faults) as marked with arrows have developed in the $\mathrm{ZnO}$ layer. An enlarged representation of the marked region is also illustrated. It suggests that the hollow $\mathrm{ZnO}$ crystals are not perfect structures. The exact reason for this subtle change in structural morphology is not clear at this stage, but it is most likely linked to dynamic crystal growth processes at different atmospheres of $\mathrm{Ar}-\mathrm{O}_{2}$ carrier gas. Although the synthesis of Zn single crystals was reported in the $1960 \mathrm{~s},{ }^{22,23}$ to the authors' knowledge, no hollow $\mathrm{Zn}$ crystals with a dimension from nanometer to micrometer were obtained at a low temperature based on the control between thermodynamics and kinetics.

Figure 6 illustrates the room-temperature photoluminescence (PL) spectra of the polygon prismatic $\mathrm{Zn}$ crystals with or without oxidization treatment. As shown in Figure 6a, no emission peak was found for the hollow Zn crystals because the polygon prismatic Zn crystals are composed solely of pure zinc metal in this case. On the contrary, as the Zn crystals were subjected to oxidation treatment (postannealing), a thin zinc oxide layer was formed on the surface of the hollow $\mathrm{Zn}$ crystals according to XRD analysis. As shown in Figure $6 \mathrm{~b}$ for the crystals annealed in air for a short time of $2 \mathrm{~h}$, ultraviolet (UV) with a peak at $380 \mathrm{~nm}$ and green emission at $\sim 500 \mathrm{~nm}$ were detected for all the $\mathrm{Zn} / \mathrm{ZnO}$ crystals. The deep-level emissions $(500 \mathrm{~nm})$ in the hollow $\mathrm{ZnO}-\mathrm{Zn}$ crystals are generally associated with defects in the $\mathrm{ZnO}$ lattice such as oxygen vacancies $\left(\mathrm{V}_{\mathrm{o}}^{* *}\right)$ and zinc interstitials $\left(\mathrm{Zn}_{\mathrm{i}}^{* *}\right)$ that are due to both lattice mismatch $(\mathrm{ZnO} / \mathrm{Zn})$ and incomplete oxidation of 
zinc. After postannealing at $300^{\circ} \mathrm{C}$ for $30 \mathrm{~h}$ in an oxygen atmosphere, the $\mathrm{PL}$ of the polygon hollow $\mathrm{ZnO}-\mathrm{Zn}$ crystals in Figure 6c illustrates that a stronger UV peak along with a relatively weak deep-level emission can be obtained. This further demonstrates that polygon prismatic hollow $\mathrm{ZnO}-(\mathrm{Zn})$ crystals can be developed at a lower temperature by thermal vapor transport. However, as compared with the $\mathrm{ZnO}$ film shown in the inset picture of Figure 6, a broader deep-level emission around $\sim 500 \mathrm{~nm}$ can still be observed for all the $\mathrm{Zn} /$ $\mathrm{ZnO}$ crystals. This indicates that more defects were generated in the polygon hollow $\mathrm{ZnO}-\mathrm{Zn}$ crystals compared to $\mathrm{ZnO}$ film deposited on $\mathrm{Si}$ by radio frequency magnetron sputtering.

\section{Conclusion}

In summary, polygon prismatic hollow $\mathrm{Zn}$ nanocrystals can be grown on a Si substrate by using liquidsolution seed nucleation along with vapor-gas growth in the low-temperature range of $300-400{ }^{\circ} \mathrm{C}$. Depending on the growth conditions (i.e., atmosphere and time), the polygon prismatic $\mathrm{Zn}$ nanocrystals with hollow and dense configuration can be produced as evidenced from AES analysis. Moreover, after prolonged oxidation, a zinc oxide thin layer can be developed on the surface of the hollow $\mathrm{Zn}$ nanocrystals to form a $\mathrm{Zn}-\mathrm{ZnO}$ coreshell structure. The room-temperature PL spectra further indicate that the UV emission can be improved by controlling the oxidation to form hollow $\mathrm{ZnO}$ nanocrystals. These formed polygon hollow $\mathrm{Zn} / \mathrm{ZnO}$ nanocrystals can be further used as building blocks to assemble twoor three-dimensional assemblies for optoelectronic device applications.

Acknowledgment. This work was financially supported by the National Science Council of Taiwan under Contract No. NSC-92-2216-E-009-014.

\section{References}

(1) Rodriguez, J. A.; Jirsak, T.; Dvorak, J.; Sambasivan, S.; Fischer, D. J.; J. Phys. Chem. B 2000, 104, 319.

(2) Hara, K.; et al. Sol. Energy Mater. Sol. Cells 2000, 64, 115.

(3) Huang, M. H.; Mao, S.; Feick, H.; Yan, H.; Wu, Y.; Kind, H.; Weber, E.; Russo, R.; Yang, P. D. Science 2001, 292, 1897.

(4) Kong, Y. C.; Yu, D. P.; Zhang, B.; Fang, W.; Feng, S. Q. Appl. Phys. Lett. 2001, 78, 407.

(5) Park, W. I.; Jun, Y. H.; Jung, S. W.; Yi, G. C. Appl. Phys. Lett. 2003, 82, 964.

(6) Zhang, Y.; Suenaga, K.; Collies, C.; Iijima, S. Science 1998, 281, 973.

(7) Pan, Z. W.; Dai, Z. R.; Wang, Z. L. Science 2001, 291, 1947.

(8) Audebrand, N.; Auffredic, J. P.; Louer, D. Chem. Mater. 1998, 10, 2450.

(9) Huang, M. H.; Wu, Y.; Feick, H.; Tran, N.; Weber, E.; Yang, P. Adv. Mater. 2001, 13, 113.

(10) Chiou, W. T.; Wu, W. Y.; Ting, J. M. Diam. Relat. Mater. 2003, 12 (10-11), 1841.

(11) Helstand, R.; Chia, Y. Mater. Res. Soc. Symp. Proc. 1996, $73,93$.

(12) Vayssieres, L.; Keis, K.; Lindquist, S.-E.; Hagfeldt, A. J. Phys. Chem. B, 2001, 105, 3350.

(13) Xie, Y.; Huang, J. X.; Li, B.; Liu, Y.; Qian, Y. T. Adv. Mater. 2000, 12, 1523.

(14) Braun, P. V.; Osenar, P.; Stupp, S. I. Nature 1996, 380, 325.

(15) Lieber, C. M. Solid State Commun. 1998, 107, 607.

(16) Alivisatos, A. P. Science 1996, 271, 933.

(17) Yamada, K.; Tobisawa, S. J. Appl. Phvs. 1989, 66, 5309.

(18) Driess, M.; Merz, K.; Schoenen, R.; Rabe, S.; Kruis, F. E.; Roy, A.; Birkner, A. C. R. Chim. 2003, 6, 273.

(19) Liu, K. H.; Lin, C. C.; Chen, S. Y.; Cheng, S. Y. J. NonCryst. Solids, submitted.

(20) Lin, C. C.; Liu, K. H.; Chen, S. Y.; Cheng, S. Y. J. Cryst. Growth, in print.

(21) Li, Y.; Meng, G. W.; Zhang, L. D.; Phillipp, F. Appl. Phvs. Lett. 2000, 76, 2011.

(22) Nanev, Chr.; Iwanov, D. Phys. Status Solidi 1967, 23, 663.

(23) Nanev, Chr.; Iwanov, D. J. Cryst. Growth 1968, 3/4, 530. CG0498150 